\title{
Succor System and Failure Indication for the Starter Batteries of Emergency Gensets
}

\author{
Annunziata D'Orazio1, Stefano Elia1*, Ezio Santini', Manuel Tobia \\ 1 Department of Astronautical, Electrical and Energy Engineering, Faculty of Civil and Industrial Engineering, Sapienza University, \\ Via delle Sette Sale 12b, 00184 Rome, Italy \\ * Corresponding author, e-mail: stefano.elia@uniroma1.it
}

Received: 16 November 2019, Accepted: 25 February 2020, Published online: 01 September 2020

\begin{abstract}
Nowadays there are $3 \%$ of missed start-ups of emergency gensets in Italian hospitals every year. The subject of this work is the analysis of the failure to start an emergency genset due to the failure of the batteries. The work is based on ten years statistics of maintenance on hospital facilities. A real case study is here described; measurements were made on a $1000 \mathrm{kVA}$ genset of a hospital to study the real operating conditions of the system. The whole electrical, mechanical and dynamic model of the starter system of a genset is studied. Computer simulations for this study are based on the Matlab/Simulink model of the considered starter system. An automatic system of parallel between the batteries of different generators is presented as a solution to the problem. This system can also indicate to the maintenance technician the need to replace a partially deteriorated battery in a timely manner. It is also proved that it is possible to succor the failed battery instantly without losing the first part of the starting transient. The work demonstrates that the failure to start, due to a fault in the batteries, can be significantly reduced by using the proposed solution. With this technical proposal the risk of blackouts and relative human losses are largely reduced.
\end{abstract}

Keywords

emergency power supply, hospital, reliability, diesel genset, starter motor, essential electrical system

\section{Introduction}

Generator sets play a fundamental role in all the structures that require continuity of power supply, for example hospitals and data centers. The redundancy offered by two (or more) gensets connected in parallel or in any configuration that allows mutual succor is the basis of this work [1].

In such environments, a possible lack of electricity represents a high-risk condition with economic or human losses, also for stand-alone micro grids, prosumers [2] and networks with unpredictable distributed production from intermittent renewable sources [3].

Smart building technology must also be applied to hospitals to allow the use of medical technology and reduce the energy impact [4]; all smart systems are based on a reliable power supply. The no-break feeding systems are generally composed of UPS and diesel gensets; UPSs cannot guarantee power supply for long periods of time, no more than one or two hours, and therefore a particularly reliable diesel generation system is required [5].

In addition to the loss of human lives, the economic loss that a blackout can give cannot be neglected [6]; numerous methods are used to predict these losses [7].
The safety of people and civil protection organizations must be carefully assessed for the design of an emergency power generation system [8].

Generally, in every building a single genset is installed; it is shown that it is necessary to design electrical systems with a double genset to guarantee a basic redundancy [9].

Nowadays technical components used to realize emergency generation systems are all valid and denote good reliability, whereas there are some deficiencies in the design of the systems that cause a decrease in power network's resilience. The design of the no-break systems must carefully forecast every disastrous event by choosing the best operating strategies, also integrating the production from renewable sources as a source of energy [10].

This work is based on a statistic analysis performed on data of 300 gensets in a period of ten years. It is noted that the most frequent failure on gensets is the failure of starter batteries, quantified at least $30 \%$ of total failures [11]. From this statistic, it is obtained a percentage of non-functioning of the genset equal to $7 \%$ of the interventions in a year. This percentage is divided into $3 \%$ 
of failures in the batteries, a $3 \%$ failure in the refueling system and a $1 \%$ relevant to the failure of the automatic transfer switch (network-genset) [9].

The aim of this work is to present a technical solution in order to prevent the failure in starting an emergency genset due to the failure of the batteries. We propose an automatic system of parallel between the batteries of different diesel generators and we demonstrate that it is possible to succor the failed battery instantly without losing the first part of the starting transient.

The mutual succor system between different batteries can be constructed using common components available on the market; moreover, the proposed system is feasible with an estimated low cost of around 1.500 euros.

The proposed model could be used to improve the sustainability of investment projects in the field of energy efficiency [12], positively affecting their riskiness.

This system can also facilitate maintenance operations, by indicating to the technicians the need to replace a partially deteriorated battery in a timely manner.

For this study, data were available of a $1000 \mathrm{kVA}$ genset of a hospital in Rome (Italy).

It is highlighted that the use of the proposed system is not obliged by any technical regulation, however in this study there are good reliability results that justify a possible request for a standardization.

\section{Tested emergency genset}

The tested genset is equipped with a Perkins 4008TAG2A diesel engine, shown in Fig. 1, coupled to a Marelli Generator MJB 400MB4-B alternator.

In Table 1 the main mechanical characteristics of interest of the diesel engine are reported.

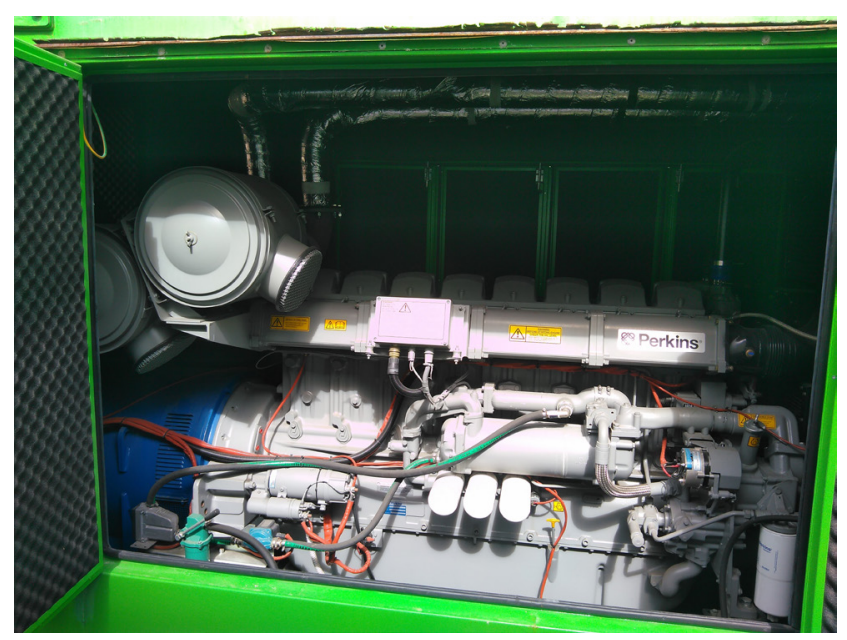

Fig. 1 Genset of the site under investigation
Table 1 Perkins 4008TAG2 diesel engine parameters

\begin{tabular}{lc}
\hline $\mathrm{N}^{\circ}$ of crown teeth starter motor coupling & 180 \\
\hline Minimum starting speed & $120 \mathrm{rpm}$ \\
\hline
\end{tabular}

Fig. 2 shows the DC starter motor; Table 2 reports its main mechanical and electrical characteristics.

Fig. 3 shows the starter batteries, Table 3 lists their main electrical characteristics.

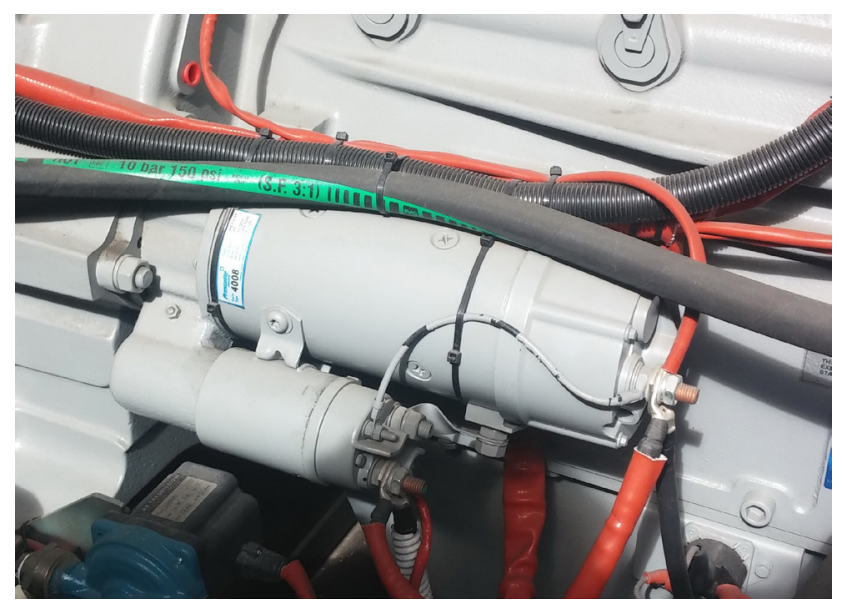

Fig. 2 Prestolite MS7-303P starter motor

Table 2 Prestolite MS7-303P starter motor characteristics

\begin{tabular}{lc}
\hline Type & DC. Series \\
\hline Rated power & $9 \mathrm{~kW}$ \\
Rated voltage & $24 \mathrm{~V}$ \\
Moment of inertia & $0.0785 \mathrm{Kg} \mathrm{m}^{2}$ \\
Time constant & $20 \mathrm{~ms}$ \\
$\mathrm{~N}^{\circ}$ of pinion teeth diesel motor coupling & 12 \\
\hline
\end{tabular}

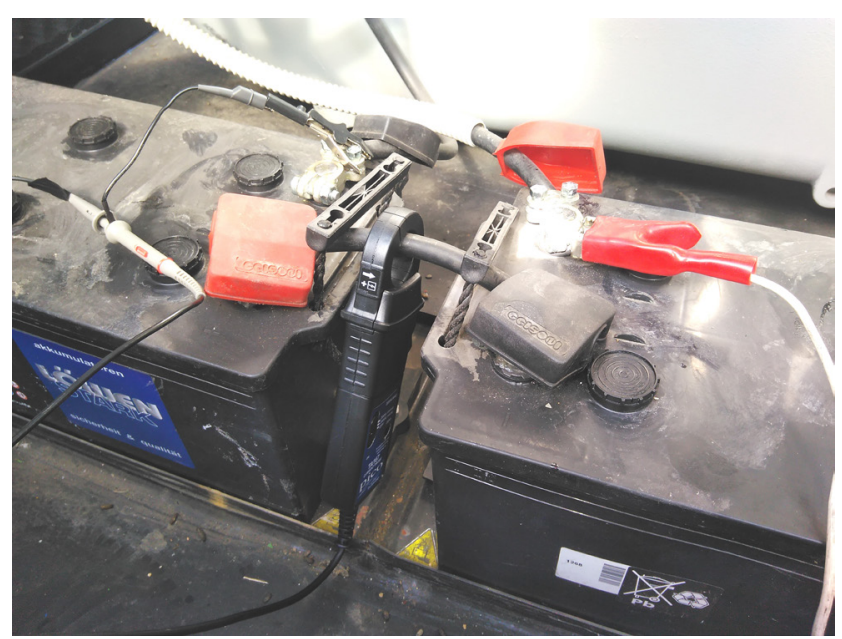

Fig. 3 Lowen Stark 12V 180 Ah starter batteries and $2000 \mathrm{~mA}$ PICO TA167 electromagnetic current transducer 
Table 3 Lowen Stark starter batteries and connection cable characteristics

\begin{tabular}{lc}
\hline $\mathrm{N}^{\circ}$ of batteries & 2 \\
\hline Connection & Series \\
Rated voltage & $12 \mathrm{~V}$ \\
Rated capacity & $180 \mathrm{Ah}$ \\
CCA & $1150 \mathrm{~A}$ \\
Connection cable section & $70 \mathrm{~mm}^{2}$ \\
Connection cable maximum length (installation manual) & $6 \mathrm{~m}$ \\
\hline
\end{tabular}

\section{Experimental data and Matlab/Simulink model}

Electrical measurements have been performed to obtain the necessary parameters for the construction of the model. A PICO 2000 oscilloscope with a $50 \mathrm{MHz}$ passband and a sampling rate of $1 \mathrm{GS} / \mathrm{s}$ was used; a $2000 \mathrm{~A}$, PICO TA167, electromagnetic current transducer with an adequate bandwidth of $20 \mathrm{kHz}$ has been added to the measurement device. Subsequently, the starter motor, the batteries and the motor-generator unit were modelled.

Based on the components datasheets, the literature information and the measured data during the start-up phase, it was possible to determine the electrical and mechanical characteristics of the starter motor shown in Fig. 4.

Table 4 shows the necessary parameters to describe the dynamic of the DC motor used in the starter system. These quantities are necessary for the model implemented through Matlab/Simulink shown in Fig. 5 [13, 14].

Lead-acid batteries, widely used for starting diesel engines [15], are generally characterized by the Shepherd model, which describes the electrochemical behavior of a battery in terms of voltage, internal resistance, discharge current and charge state $[16,17]$. These parameters can be obtained from the technical sheets supplied by the manufacturer [18].

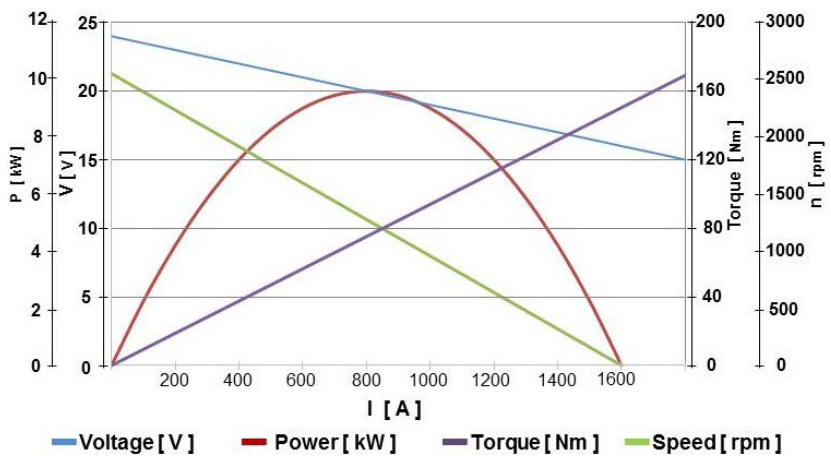

Fig. 4 Starter motor performance
Table 4 Prestolite MS7-303P starter motor electromechanical characteristics

\begin{tabular}{lcc}
\hline Variable & Symbol & Value \\
\hline Rated voltage & $V n$ & $24 \mathrm{~V}$ \\
Power & $P n$ & $9 \mathrm{~kW}$ \\
Moment of inertia & $J$ & $0.0785 \mathrm{kgm}^{2}$ \\
Time constant & $\tau$ & $20 \mathrm{~ms}$ \\
Total resistance & $R$ & $10 \mathrm{~m} \Omega$ \\
Total inductance & $L$ & $20 \mu \mathrm{H}$ \\
Torque costant & $K t$ & $0.094 \mathrm{Nm} / \mathrm{A}$ \\
CEMF costant & $K e$ & $0.0094 \mathrm{~V} / \mathrm{rpm}$ \\
\hline
\end{tabular}

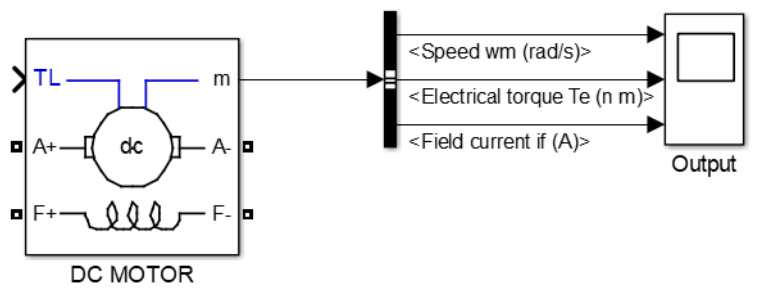

Fig. 5 Starter motor Matlab/Simulink model

In order to implement the battery simulation model, it is necessary to state the following assumptions:

- the internal resistance of the battery is supposed constant during the discharge cycles and does not vary with the amplitude of the current;

- the battery capacity does not vary with the amplitude of the current (no Peukert effect);

- the temperature does not influence the phenomenon;

- the phenomenon of battery self-discharge is not considered;

- the memory effect of the battery is not considered.

The Shepherd model implies:

$$
\begin{aligned}
& V_{\text {batt }}(t)=E_{0}-R \times i(t)-\frac{K \times Q}{(Q-i t) \times\left(i t+i^{*}\right)}+\operatorname{Exp}(t), \\
& \operatorname{Exp}(t)=B \times|i(t)| \times[-\operatorname{Exp}(t)+A \times u(t)] .
\end{aligned}
$$

In Eqs. (1) and (2), $V_{\text {batt }}(t)$ is the voltage at the terminals [V], $E_{0}$ is the no-load voltage [V], $K$ is the polarization constant or polarization resistance [V/Ah], $Q$ is the capacity of the battery [Ah], it is the discharged capacity [Ah], $R$ is the internal resistance of the battery [ $\Omega]$. In addition, $i(t)$ is the dynamic battery current at time " $t$ " $[\mathrm{A}], i^{*}$ represents the current filtered through polarization resistance [A], $\operatorname{Exp}(t)$ is the voltage in the exponential zone (discharge 
characteristic of the battery), $u(t)$ indicates the charging mode (when equal to 1 ) or discharge mode (when equal to 0 ) of the battery [19]. $A$ and $B$ are parameters obtained from the battery datasheet (charge and discharge characteristics of lead-acid batteries): $A$ is the amplitude of the exponential area $[\mathrm{V}], B$ is the inverse of the time constant of the exponential zone $\left.\left[\mathrm{Ah}^{-1}\right]\right)$. Fig. 6 shows the starter battery model section in the Matlab/Simulink framework.

The diesel engine and the alternator are considered only with reference to their contribution to the starting system. Their torques and moments of inertia are considered by means of the transmission ratio of the crown-pinion unit, which is equal to 15 .

The starter motor behaves according to Eq. (3):

$J \times \frac{d \omega}{d t}=T_{M}-T_{L}$,

where $J$ represents the moment of inertia of the rotating mass, $\omega$ the angular velocity, $T_{M}$ the electromagnetic torque generated by the motor itself and $T_{L}$ the resistant torque applied to the motor shaft [20].

It is worth noting that the resistant torque $T_{L}$, which the internal combustion engine exhibits when it is started, is a parameter characterized by a non-linear behavior, which in the starting phase can be expressed through:

$T_{L}=T_{C}+T_{F}+J \times \frac{d \omega}{d t}$,

where $T_{L}$ is the total resistant torque of the diesel engine, $T_{C}$ is the torque of the cylinder-piston system, $T_{F}$ is the friction torque and $J$ represents the moment of inertia of the diesel engine and the alternator coupled to its engine shaft.

The resistant torque of the diesel engine - alternator group, in absence of the necessary technical data, is evaluated by means of experimental measurements of current, time and speed, directly on the starter motor.
The torque, that must be contrasted by the starter motor through a transmission ratio equal to 15 , is represented in Fig. 7 as a function of the speed.

Fig. 8 shows the Matlab/Simulink model of the whole genset starting system.

\section{Model validation}

Through the measurement instrumentation, the voltage at the battery terminals and the current absorbed by the starter motor during the diesel engine starting phase are determined; their values as a function of the time are shown in Fig. 9.

The Matlab/Simulink model is validated by direct comparison with the performed measurements. In Fig. 10 and Fig. 11 the simulation results in comparison with experimental results are shown, for voltage and current respectively.

Comparing the measured data and the data provided by the simulation model, it is possible to observe that the maximum percentage difference between the curves is less than $10 \%$. This is due to the non-linearity of the real system, not simulated in the model.

\section{Simulation results}

\subsection{Starting without battery succor system}

According to the datasheet, the minimum starting speed of the diesel engine is $120 \mathrm{rpm}$ [21]; this speed value refers to the case of a good state of maintenance and preheated engine. Therefore, by considering the transmission ratio equal to 15 , the diesel engine starts when the starter motor reaches $1900 \mathrm{rpm}$. All the simulations are performed by considering the exceeding of this rotation speed as satisfactory for motor start-up. The degradation of the batteries is simulated by increasing appropriately the internal resistance corresponding to the state of each test condition.

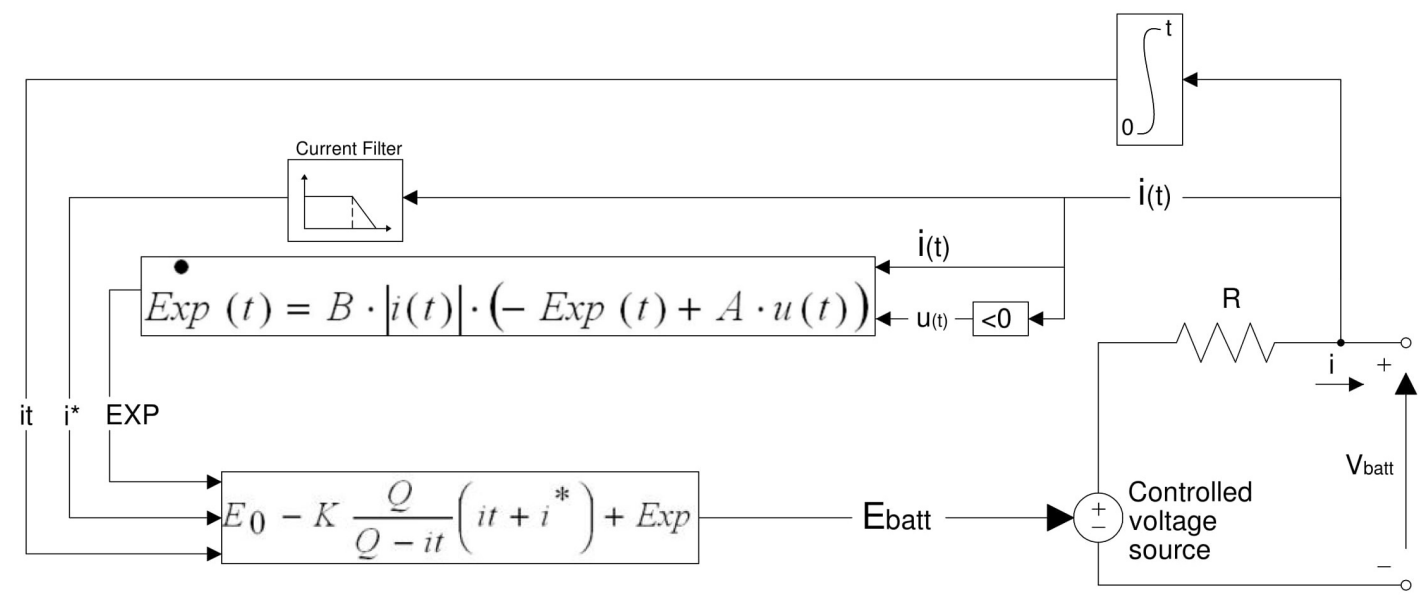

Fig. 6 Starter batteries in Matlab/Simulink model 


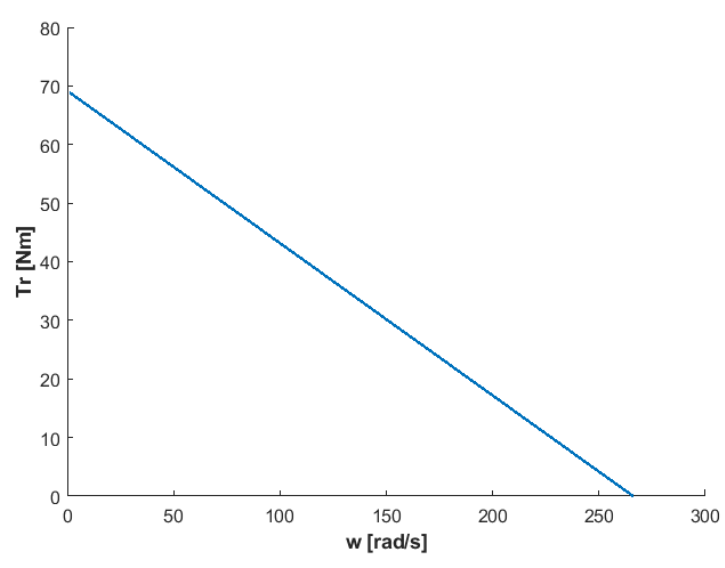

Fig. 7 Starter motor resistant torque by angular speed

Thus, new batteries can be compared with degraded batteries (at the end of its useful life).

Table 5 summarizes the results, obtained from the simulations of the starting system without a battery succor system, for different State of Charge of the batteries (SOC), in case of new and degraded batteries. The conditions for successful start-up are shown in green, while the failed start-up events are highlighted in red.

From the performed simulations, the voltage variation of the batteries is obtained according to their state [22]. The chart in Fig. 12 shows the trends of the battery voltage according to the SOC and degradation state; the cases of failed start-up are highlighted in red, the cases of successful motor start-up in green.

From tests and measurements, it is defined a threshold value of the voltage below which the motor starting fails. This critical voltage is equal to $12.6 \mathrm{~V}$, corresponding to a new battery with SOC equal to $40 \%$ and to a degraded battery with SOC equal to $100 \%$.

\subsection{Starting with battery succor system}

Once the threshold voltage that defines the failed startup status is determined, an alarm can be activated. Our proposal is that the alarm signal could be used to instantly activate a succor system, obtained by means of a parallel connection between the batteries of two different gensets; if another genset is not present, a spare battery pack can be used to start the genset anyway on the first attempt.

The succor between the batteries occurs by closing a contactor $(\mathrm{K})$ that connects the positive contacts of the two starting systems, as shown in Fig. 13. Each genset has an auxiliary circuit (powered for improving reliability by the other group in a crossed manner) which activates the contactor $(\mathrm{K})$ in case of battery voltage below the threshold value by means of a minimum voltage relay (RM). To further improve the reliability of the succor system a reliable electromechanical minimum voltage relay, immersed in insulating oil, has been specially designed [23, 24]. Furthermore, each auxiliary system has an additional relay (B1A and B2A) which remains in self-excitation with the light on (A1 or A2), in case of activation, to indicate the failure event. This indication is important in order to understand which of the two groups has the battery that needs to be replaced. The alarm is deactivated by pressing the reset switch ( $\mathrm{R} 1$ or R2). It is highlighted that the succor system also presents a manual switch (MC1 and MC2).

Fig. 14 shows the Matlab/Simulink model of the starting system of two gensets and the set of functional components designed to simulate the operation of the battery succor system. It can be noticed that the parallel battery contactor has been simulated as an ideal switch of zero internal resistance.

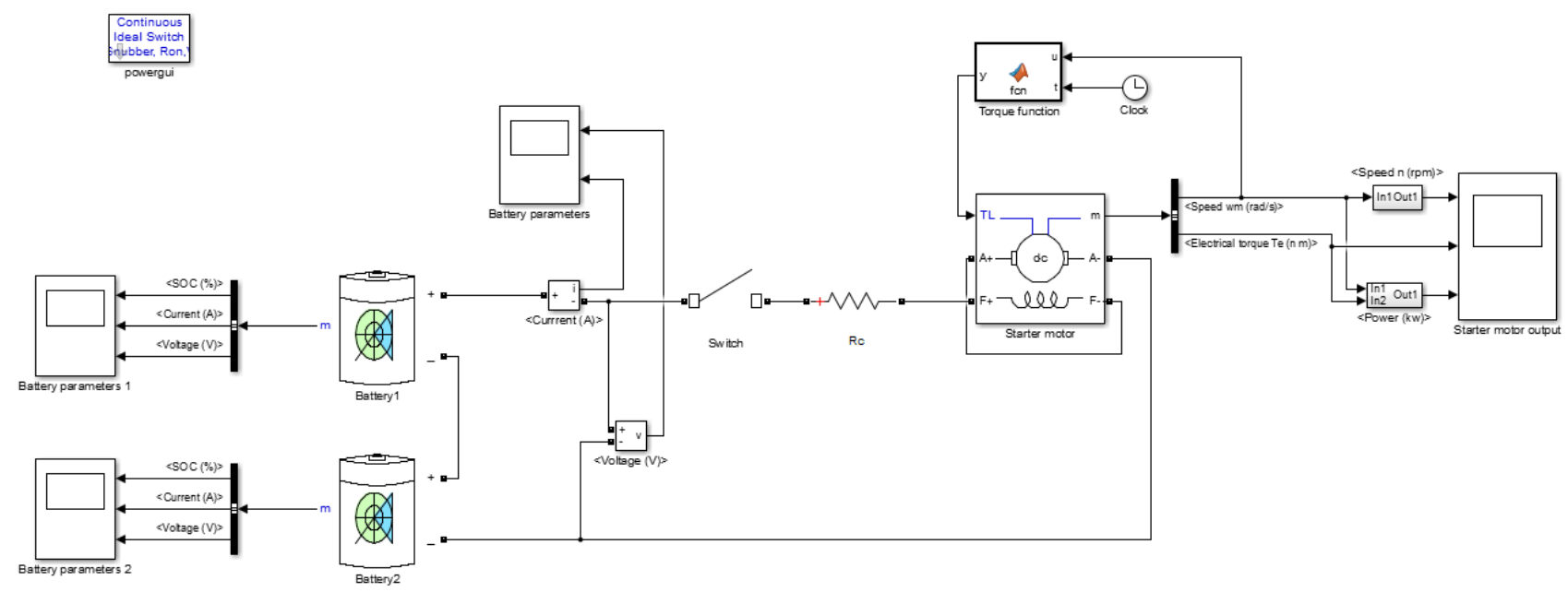

Fig. 8 Starting system Matlab/Simulink model 


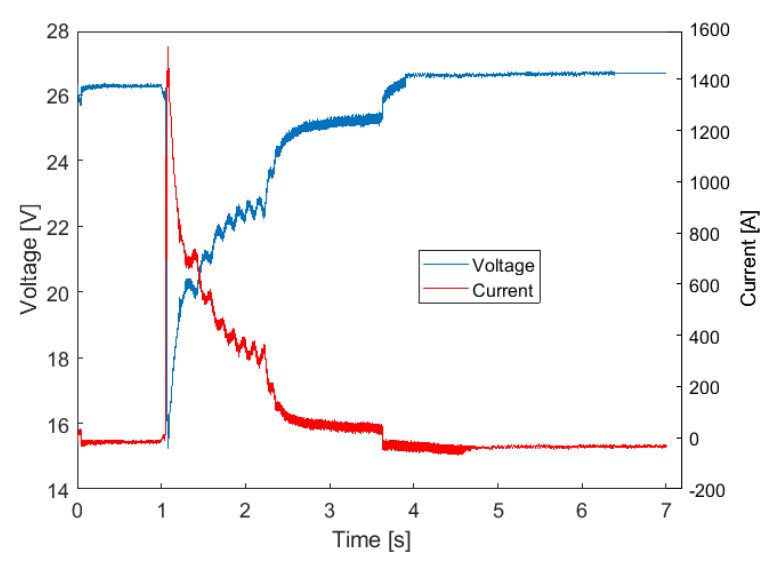

Fig. 9 Startup transient with starter motor voltage and current

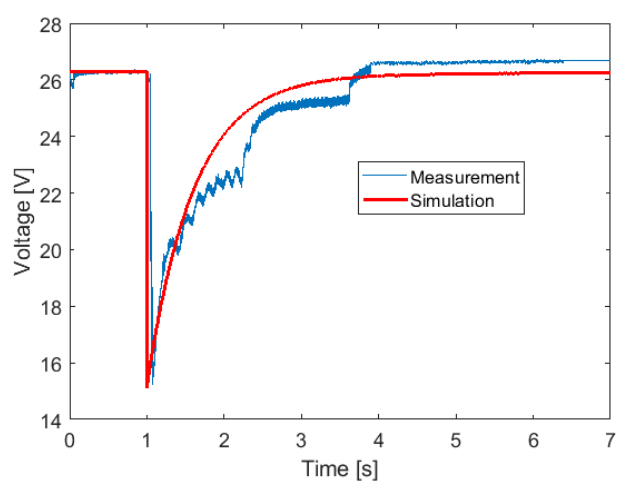

Fig. 10 Comparison between measured and simulated voltage

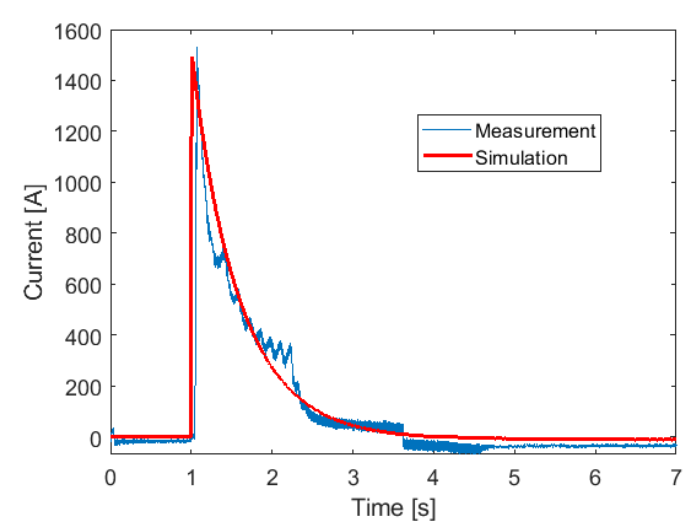

Fig. 11 Comparison between measured and simulated current

Using the Matlab/Simulink model, the numerical value of the resistance of the succor cable was determined, when a single battery (new, with $\mathrm{SOC}=40 \%$ ) would be able to autonomously start both gensets. The limit value is equal to $0.002 \Omega$, which is necessary for the sizing of the parallel cable section. This resistance value of the cable was used in the simulations to consider the worst case.

Afterwards, the start-up simulations of the two gensets were performed. Considering for each battery the two extreme cases of degradation (new battery and totally degraded battery), and by varying the State of Charge,
Table 5 Genset starting without the mutual battery succor system

\begin{tabular}{ccc}
\hline SOC $[\%]$ & New batteries & Degraded batteries \\
\hline 100 & STARTED & STARTED \\
90 & STARTED & STARTED \\
80 & STARTED & STARTED \\
70 & STARTED & STARTED \\
60 & STARTED & FAILED \\
50 & STARTED & FAILED \\
40 & STARTED & FAILED \\
30 & FAILED & FAILED \\
20 & FAILED & FAILED \\
10 & FAILED & FAILED \\
\hline
\end{tabular}

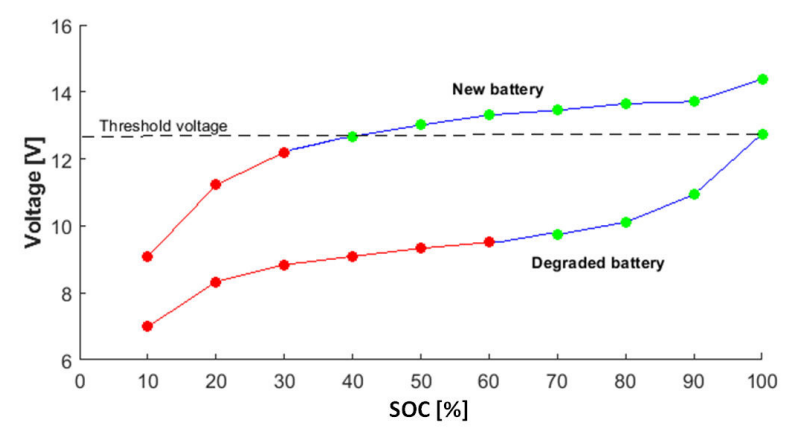

Fig. 12 Battery voltage as a function of the SOC and degradation

the outcomes of the simulations were obtained as successful start-up events or failed ones. In the look up tables of Fig. 15, Fig. 16 and Fig. 17, the green cells are linked to the success of the succor system while the red cells to the missed succor. The yellow cells represent events for which the start-up of the gensets can be verified but not guaranteed.

From the figures, one can see that the event of failed start-up with the succor system has a non-negligible probability if both batteries are at the same time degraded and discharged. This combination is very rare, since in the periodic test the first of the two batteries that is degraded indicates preventively via the mutual succor system the need for replacement.

\section{Conclusions}

The analysis of the genset cranking phase was carried out thanks to the implementation of a specially designed mathematical model of the entire starting system.

This was also possible thanks to the collection of technical data by maintenance technicians, which lasted a good ten years, and a field measurement campaign.

This essential model has been exploited to perform all the tests here described and to verify the validity of the proposed technical solution. 


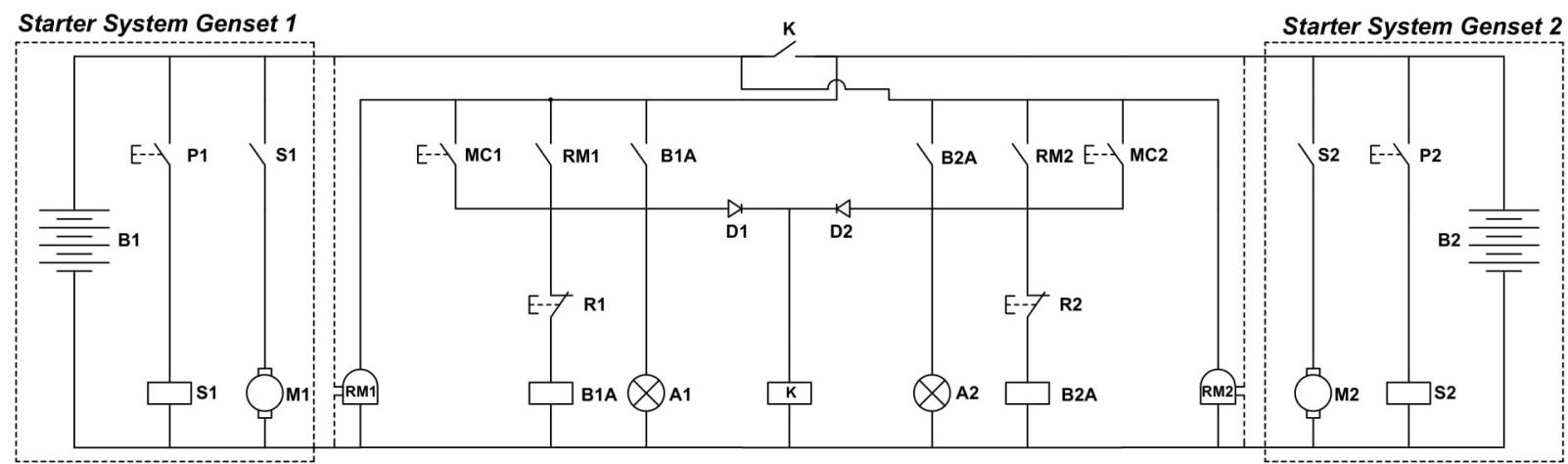

Fig. 13 Mutual succor system

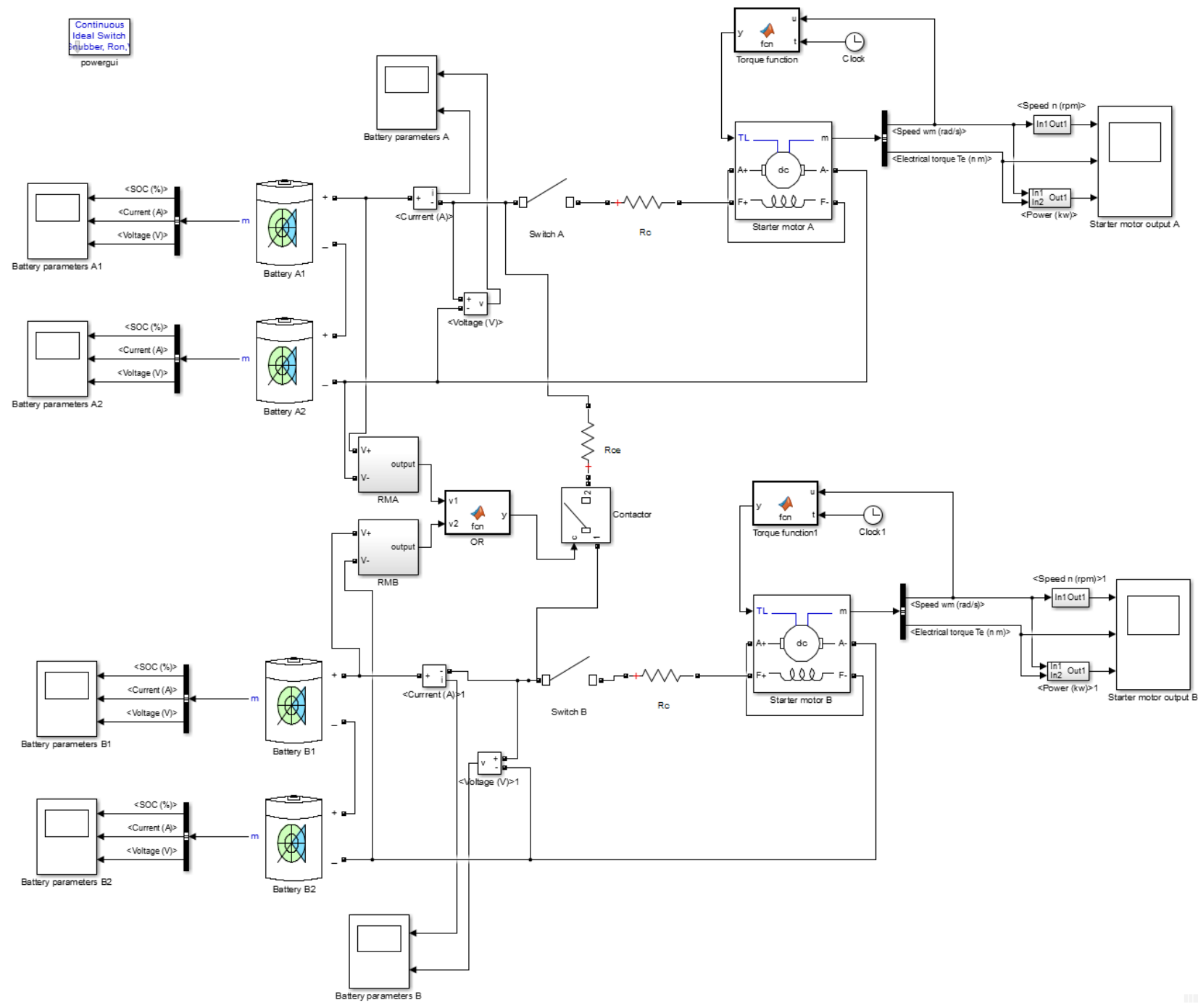

Fig. 14 Simulink model of the complete succor system

The model is implemented on the Matlab/Simulink platform for ease of use and divulgation possibilities.

Deterioration of the batteries and variation of the State of Charge have been taken in account; the cases in which the batteries are able or not to start the genset have been precisely determined.
The proposed battery succor system instantly connects in parallel two battery packs of two different gensets, during the cranking phase, only when one of them is damaged or discharged. In this way, it is shown that a failed start-up is possible only if both batteries are strongly discharged and degraded. In the limit case of both degraded 


\begin{tabular}{|c|c|c|c|c|c|c|c|c|c|c|c|c|}
\hline & & & & & & SET & $\mathrm{NE}$ & BA & ERY & & & \\
\hline & SOC\% & 100 & 90 & 80 & 70 & 60 & 50 & 40 & 30 & 20 & 10 & 0 \\
\hline & 100 & & & & & & & & & & & \\
\hline & 90 & & & & & & & & & & & \\
\hline 兑 & 80 & & & & & & & & & & & \\
\hline$\frac{5}{4}$ & 70 & & & & & & & & & & & \\
\hline$\sum$ & 60 & & & & & & & & & & & \\
\hline 焉 & 50 & & & & & & & & & & & \\
\hline$\infty$ & 40 & & & & & & & & & & & \\
\hline $\bar{\omega}$ & 30 & & & & & & & & & & & \\
\hline 兑 & 20 & & & & & & & & & & & \\
\hline & 10 & & & & & & & & & & & \\
\hline & 0 & & & & & & & & & & & \\
\hline
\end{tabular}

Fig. 15 Starting simulation with battery succor system, new batteries

\begin{tabular}{|c|c|c|c|c|c|c|c|c|c|c|c|c|}
\hline & & & & & SENS & TAL & ERA & DED & АTTE & & & \\
\hline & SOC\% & 100 & 90 & 80 & 70 & 60 & 50 & 40 & 30 & 20 & 10 & 0 \\
\hline & 100 & & & & & & & & & & & \\
\hline & 90 & & & & & & & & & & & \\
\hline & 80 & & & & & & & & & & & \\
\hline$\frac{k}{4}$ & 70 & & & & & & & & & & & \\
\hline$\sum$ & 60 & & & & & & & & & & & \\
\hline$\underline{z}$ & 50 & & & & & & & & & & & \\
\hline$\infty$ & 40 & & & & & & & & & & & \\
\hline$\sqrt{\omega}$ & 30 & & & & & & & & & & & \\
\hline z & 20 & & & & & & & & & & & \\
\hline & 10 & & & & & & & & & & & \\
\hline & 0 & & & & & & & & & & & \\
\hline
\end{tabular}

Fig. 16 Starting simulation with battery succor system, one new battery and one degraded battery

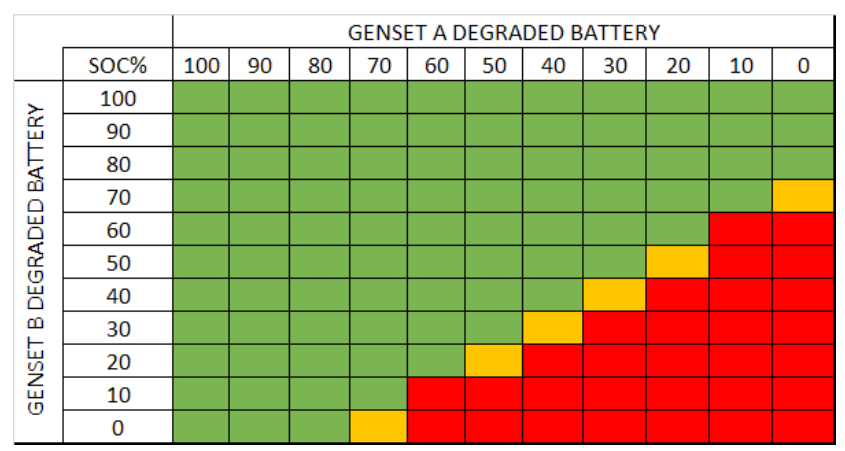

Fig. 17 Starting simulation with battery succor system, both degraded batteries

batteries, with SOC equal to $40 \%$, the genset starting is however guaranteed and the low-battery alarm is also activated.

\section{References}

[1] Elia, S., Santantonio, A. "Fire Risk in MTBF Evaluation for UPS System", Advances in Electrical and Electronic Engineering, 14(2), pp. 189-195, 2016.

https://doi.org/10.15598/aeee.v14i2.1662

[2] Muzi, F., Calcara, L., Sangiovanni, S., Pompili, M. "Smart Energy Management of a Prosumer for a Better Environment Safeguard", 2018 AEIT International Annual Conference, Bari, Italy, 2018, pp. $1-5$.

https://oi.org/10.23919/AEIT.2018.8577434
It is highlighted that the periodic start-up test, usually monthly, allows to continuously check of the state of the batteries through the calibrated relay. If the battery monitoring relay trips when the alarm is activated, the maintenance technician is warned in advance of the necessary replacement of a battery. The maintenance test here proposed for the energy storage is highly effective, because the batteries are periodically tested with the real starting load current.

With the proposed system and the periodic maintenance start-up procedure, the possibility of having a battery at the end of its life is almost completely eliminated.

Given the impossibility of completely eliminate the probability of failure to start up, in order to add further redundancy to the power supply system, the proposed succor system is also considered appropriate to operate as an emergency switching system for interconnection of the power loads on the different gensets [9].

The proposed model could be considered in the context of investment projects modeled with public-private partnership schemes, already studied in the health [4, 25], CED, rural areas [26], tunnels [27] and other sectors [28-30], in consideration of the benefit that it could bring in terms of risk mitigation.

The ever-increasing use of renewable sources in the production of energy, given their unpredictability, favors the instability of the grid and increases the possibility of blackouts [3]. For this reason it becomes essential to increase the reliability of power supply systems in vulnerable places, such as hospitals.

Moreover, the proposed succor system between batteries can be assembled using commercially available components with an estimated low cost of about 1.500 euros.

\section{Acknowledgment}

This work was performed with the operative support on data collection by ENGIE maintenance supervisor Mario Longo.

[3] Iannarelli, G., Boccaletti, C. "Economic impact of investments in weather forecasts for distribution system operators: the Italian case", IET Digital Library, 12(20), pp. 4551-4556, 2018.

https://doi.org/10.1049/iet-gtd.2017.1919

[4] Visconti, R. M., Martiniello, L., Morea, D., Gebennini, E. "Can Public-Private Partnerships Foster Investment Sustainability in Smart Hospitals?", Sustainability, 11(6), Article Number: 1704, 2019.

https://doi.org/10.3390/su11061704 
[5] Angays, P. "What To Do If You Are Afraid of the Dark: Recommendations for the Design of Electrical Backup Systems", IEEE Industry Applications Magazine, 19(1), pp. 49-59, 2013. https://doi.org/10.1109/MIAS.2012.2216001

[6] Wang, C., He, H., Zhu, T. X. "Impacts of the Blackout on August 14 on the Renovation of Power Market in China", In: ESMO 2006 2006 IEEE 11th International Conference on Transmission \& Distribution Construction, Operation and Live-Line Maintenance, Albuquerque, NM, USA, 2006.

https://doi.org/10.1109/TDCLLM.2006.340721

[7] Liang, Z. H., Zhou, Y. H., Gu, H. F., Wang, Y. L., Hu, Z. H. "An approach for the estimation of the accident cost of distribution network failure based on fuzzy theory", In: 2008 China International Conference on Electricity Distribution, Guangzhou, China, 2008, pp. 1-5. https://doi.org/10.1109/CICED.2008.5211665

[8] Xing, J., Xiangyu, M., Tianmeng, Y., Na, Z., Zhuoran, S. "Evaluation of Blackout Social Comprehensive Loss Based on Public Security Model", In: 2018 China International Conference on Electricity Distribution (CICED), Tianjin, China, 2018, pp. 861-866. https://doi.org/10.1109/CICED.2018.8592145

[9] Elia, S., Santini, E., Tobia, M. "Comparison between Different Electrical Configurations of Emergency Diesel Generators for Redundancy and Reliability Improving", Periodica Polytechnica Electrical Engineering and Computer Science, 62(4), pp. 144-148, 2018. https://doi.org/10.3311/PPee.13242

[10] Ihara, T., Tanaka, K. "Electricity management for persuing green and resilient airport in case of disaster: Including renewable energy sources, batteries, and diesel generators", In: 2016 IEEE 16th International Conference on Environment and Electrical Engineering (EEEIC), Florence, Italy, 2016, pp. 1-4. https://doi.org/10.1109/EEEIC.2016.7555717

[11] Du, P. Y., Burnett, J., Chan, S. M. "Reliability of standby generators in Hong Kong buildings", IEEE Transactions on Industry Applications, 39(6), pp. 1592-1595, 2003. https://doi.org/10.1109/TIA.2003.818978

[12] Campisi, D., Gitto, S., Morea, D. "An Evaluation of Energy and Economic Efficiency in Residential Buildings Sector: A Multicriteria Analisys on an Italian Case Study", International Journal of Energy Economics and Policy, 8(3), pp. 185-196, 2018. [online] Available at: http://econjournals.com/index.php/ijeep/article/ view/6255 [Accessed: 22 July 2019]

[13] Enache, B. A., Constantinescu, L. M., Lefter, E. "Modeling aspects of an electric starter system for an internal combustion engine", In: Proceedings of the 2014 6th International Conference on Electronics, Computers and Artificial Intelligence (ECAI), Bucharest, Romania, 2014, pp. 39-42. https://doi.org/10.1109/ECAI.2014.7090177

[14] Wickramasinghe, W. M. H. R., Duleeka, K. T. G. M., Kolamunna, H. D., Abeyratne, S. G. "A power electronics assisted emergency vehicle starter", In: 2014 16th International Power Electronics and Motion Control Conference and Exposition, Antalya, Turkey, 2014, pp. 283-288. https://doi.org/10.1109/EPEPEMC.2014.6980506
[15] Robert Bosch GmbH "Bosch Automotive Electrics and Automotive Electronics: Systems and Components, Networking and Hybrid Drive", Springer Vieweg, Wiesbaden, Germany, 2014. https://doi.org/10.1007/978-3-658-01784-2

[16] Tremblay, O., Dessaint, L. A. "Experimental Validation of Battery Dynamic Model for EV Application", World Electric Vehicle Journal, 3(2), pp. 289-298, 2009. https://doi.org/10.3390/wevj3020289

[17] Gatta, F. M., Geri, A., Lamedica, R., Lauria, S., Maccioni, M., Palone, F., Rebolini, M., Ruvio, A. "Application of a $\mathrm{LiFePO}_{4}$ Battery Energy Storage System to Primary Frequency Control: Simulations and Experimental Results", Energies, 9(11), Article Number: 887, 2016. https://doi.org/10.3390/en9110887

[18] CAT "Application \& Installation Guide: Starting Systems", Caterpillar Inc., 2016. [online] Available at: http://s7d2.scene7. com/is/content/Caterpillar/CM20160713-53120-43186 [Accessed: 10 July 2019]

[19] Tremblay, O., Dessaint, L. A., Dekkiche, A. I. "A Generic Battery Model for the Dynamic Simulation of Hybrid Electric Vehicles", In: 2007 IEEE Vehicle Power and Propulsion Conference, Arlington, TX, USA, 2007, pp. 284-289. https://doi.org/10.1109/VPPC.2007.4544139

[20] Mundhe, S. "Engine motoring torque estimation", Cummins, [online] 13 October 2014. Available at: https://www.gtisoft.com/ wp-content/uploads/publication/Cummins_Engine_Motoring _ Torque.pdf [Accessed: 08 March 2018]

[21] Perkins "Diesel engine electrounit, Technical Data 4000 series", Perkins Inc., 2014. [online] Available at: https://www. perkins.com/en_GB/products/product-range/4000-series.html [Accessed: 15 May 2018]

[22] Murugesan, V. M., Rudramoorthy, R., Chandramohan, G., Senthil Kumar, M., Ashok Kumar, L., Vishnu Murthy, K., Suresh Kumar, R. "Development of ECU Based Starting System for Automobiles", In: 2011 International Conference on Process Automation, Control and Computing, Coimbatore, India, 2011, pp. $1-5$. https://doi.org/10.1109/PACC.2011.5978987

[23] Elia, S., Ruvio, A., Bracci, D. "A study on a high-reliability electromechanical undervoltage relay immersed in natural ester oil: application in mutual aid system for gensets using", In: 2019 IEEE 20th International Conference on Dielectric Liquids (ICDL), Roma, Italy, 2019, pp. 1-4. https://doi.org/10.1109/ICDL.2019.8796685

[24] Pompili, M., Calcara, L., Sangiovanni, S., Scatiggio, F., Mazzaro, M., De Bartolomeo, D. "Natural Esters and Mineral Oils Fire Behavior", In: 2018 IEEE 2nd International Conference on Dielectrics (ICD), Budapest, Hungary, 2018, pp. 1-4. https://doi.org/10.1109/ICD.2018.8468447

[25] Parise, G., Parise, L., Martirano, L., Germole, A. "Service Continuity Safety by Design: The Relevance of Electrical PowerSystem Architectures in Hospitals", IEEE Industry Applications Magazine, 22(1), pp. 68-74, 2016. https://doi.org/10.1109/MIAS.2015.2459533 
[26] Parise, G., Martirano, L., Parise, L. "Electric Infrastructures Equalized to Strategic for Disaster Recovery in Emergencies", In: 2018 IEEE International Conference on Environment and Electrical Engineering and 2018 IEEE Industrial and Commercial Power Systems Europe (EEEIC / I\&CPS Europe), Palermo, Italy, 2018, pp. 1-5.

https://doi.org/10.1109/EEEIC.2018.8494378

[27] Focaracci, A., Greco, G., Martirano, L. "Dynamic Risk Analysis and Energy Saving in Tunnels", In: 2019 IEEE International Conference on Environment and Electrical Engineering and 2019 IEEE Industrial and Commercial Power Systems Europe (EEEIC / I\&CPS Europe), Genova, Italy, 2019, pp. 1-6. https://doi.org/10.1109/EEEIC.2019.8783288

[28] Gad, M., Abualhaol, I. "Securing Smart Cities Systems and Services: A Risk-Based Analytics-Driven Approach", In: Mouftah, H. T., Erol-Kantarci, M., Rehmani, M. H. (eds.) Transportation and Power Grid in Smart Cities: Communication Networks and Services, Wiley, Hoboken, NJ, USA, 2019, pp. 577-589. https://doi.org/10.1002/9781119360124.ch22
[29] Morea, D., Balzarini, M. "Financial sustainability of a public-private partnership for an agricultural development project in Sub-Saharan Africa", Agricultural Economics, 64(9), pp. 389-398, 2018. https://doi.org/10.17221/161/2017-AGRICECON

[30] Morea, D., Balzarini, M. "Bankability of a public private partnership in agricultural sector: A project in Sub Saharan Africa", Agricultural Economics, 65(5), pp. 212-222, 2019. https://doi.org/10.17221/258/2018-AGRICECON 